\title{
Pluralism and Deliberation
}

\author{
Matteo Bianchin - Università di Milano-Bicocca
}

in V. Kaul, I. Salvatore (eds.). What is Pluralism? London: Routledge 2020: 31-47

Penultimate draft

\section{Pluralism: Some Varieties}

A minimal, possibly uncontroversial, characterization of pluralism requires the same thing to be understood differently, as it seems that there is nothing to disagree about where different people talk or think of different things. ${ }^{1}$ Pluralism is commonly intended to convey the notion that, at least on certain matters, more than one view is rationally allowed, such that two people may disagree on a given question, yet both be justified in their beliefs. However, it is not trivial to see how this might work. Rawls' early distinction between the concept and conceptions of justice, for example, suggests that we can disagree about the nature of justice, while agreeing that being just is a property of institutions designed to assign basic rights and to regulate the distribution of the burdens and benefits of cooperation in a well-ordered society. It is far from obvious, however, that this leaves room for pluralism. In fact, it was not Rawls' view in A Theory of Justice that it does.

Rawls took the concept of justice to express what the different conceptions of justice "have in common" in terms of basic properties that just institutions necessarily possess, such as that of making "no arbitrary difference among persons in the assigning of rights and duties" and that of determining "a proper balance between competing claims to the advantages of social life" (Rawls 1971: 5). People that disagree on the set of principles that should specify the basic terms of their association may recognize that each have a conception of justice as long as they agree about the essential properties of just institutions, while leaving open the interpretation of 
the notions of an arbitrary distinction and of a proper balance Rawls 1971: 5). Although the latter are intended by Rawls to offer a "description" of just institutions in terms of the notions "included in the concept of justice", one might be tempted to draw a parallel with natural kind terms (Putnam 1975: $215 \mathrm{ff}$.). While the reference of the concept of justice may not be fixed by any microphysical fact, it is likely to be fixed by a set of facts concerning social institutions for example, their conforming to principles that can gain acceptance under qualified conditions and the psychological background required to settle those conditions - where the nature of the relevant facts is the object of the theory of justice. Thus, we might be open to the possibility that just institutions are a social kind and that the concept of justice behaves like a kind term whose content is fixed by the way the (social) world is, while different conceptions of justice represent different theories about just institutions that may be assessed with respect to a variety of factors, in particular with respect to how they respond to the demand for efficiency, coordination, and stability raised on just institutions (Rawls 1971: 6). The relevant facts will of course largely, although perhaps not fully, depend on human behaviors, actions, and attitudes. Yet this does not preclude the concept of justice from having its content fixed referentially. If we are permissive enough to grant that mind-dependent properties such as being a doorknob fix the content of the relevant concepts (Fodor 1998: 148 ff.), there is no reason why the content of social kind terms should not be fixed by social properties, however complex their metaphysics may turn out to be. ${ }^{2}$

On this \reading, there may at best be one single correct conception of justice, although people disagree about the nature of the facts that determine the correctness of claims about justice, that is about the truth conditions of those claim (Valentini 2013). Still, in this case, people will disagree as a consequence of diverging in the reasons they take to be relevant to settling the issue. Different conceptions of justice will thus differ in terms of the justification they provide for their respective claims about the nature of just institutions, while their proponents would agree that there is a determinate answer to the question. A prima facie case for pluralism can be made in this connection by arguing that what count as relevant reasons widely differ across persons, communities, and cultures as a consequence of their endorsing different sets of norms, standards, or principles for forming beliefs and judgments. Pluralism here does not concern the metaphysics, but the epistemology of justice. It does not amount to the claim that there are different ways in which things may turn out to be - the claim that the facts about just institutions are relative to the way in which justice is conceived - but to the 
claim that there are different ways in which beliefs and judgments about justice may be assessed. Telling epistemology apart from metaphysics thus helps us to make sense of the idea that there may be a genuine case for pluralism in relation to justice. ${ }^{3}$ The interesting case rests on whether we can expect convergence in this domain among people talking and thinking about the same thing. The claim for pluralism here concerns the standards, methods, and norms for forming belief and judgment about certain kinds of facts, rather than the nature of facts themselves.

Borrowing from epistemology, however, we may distinguish between a descriptive and a normative understanding of this claim. Descriptive pluralism is the "simple, non-normative thesis that different communities, cultures, networks, and so on, endorse different epistemic systems - that is, different set of norms, standards, or principles for forming beliefs and other doxastic states" (Goldman 2010: 187). This weak, descriptive reading allows for principled ways to adjudicate controversial issues. Disagreement follows from the fallible nature of our rational capacities, the limited evidence we have access to, the different background beliefs and collateral information each of the parties relies on, and different methods and norms for forming beliefs and judgment. Yet disagreement in this case is virtually contingent, given that no principled limit is set to the possibility of arguing about evidence and the standards by which it is assessed. Nothing prevents even basic background assumptions and fundamental epistemic principles from being subject to critical reflection so that disagreements may, on principle, be settled by argument (Feldman 2007: 206). Pluralism here ultimately collapses into a modest, reasonably uncontroversial, fallibilistic claim. People are allowed to diverge, because they happen to form their beliefs and judgments in different ways, yet they may be expected to converge in the long run, at least under epistemically ideal conditions. The converse, normative view is that there is a plurality of epistemic systems, yet no fact of the matter about which is the right or better one (Goldman 2010. 188). According to this stronger reading disagreement may run deep, given that there are different sets of norms, standards or principles governing how beliefs and judgments are formed, but there is no fact of the matter as to whether some of them are more correct than others. This kind of pluralism differs from descriptive pluralism in that it takes stance on the normative issue of whether some norms, standards or principles are better than others. On this normative reading, however, pluralism entails a hardly feasible relativist claim that follows from the conjunction of three claims: (1) there are no absolute facts about what a particular item of information justifies; (2) judgments such as "E justifies belief 
B" express the claim: "According to the epistemic system C, information E justifies belief B"; (3) there are many fundamentally different, genuinely alternative epistemic systems, but no facts by virtue of which one of these systems is more correct than any of the others (Boghossian 2006: 73). In this case, there seems to be no way in which agreement can be reached by argument about deeply controversial issues, because people holding different epistemic system diverge on what may count as a reason for belief.

The lesson seems to be that, if pluralism is to have a distinct standing, it needs to rest on grounds that are stronger than fallibilism, yet weaker than relativism, thus ruling out both "deep" disagreement and the view that convergence can be expected. For on the one hand, relativism would be vindicated, if disagreement would follow from "a clash of framework propositions" and/or "underlying principles" that "cannot be resolved through the use of argument", for in this case the conditions essential to arguing are undercut (Fogelin 1985: 8). While, on the other hand, fallibilism would be sufficient to account for disagreement, if it would be sensible to expect convergence. A viable understanding of pluralism thus seems to involve recognizing that, at least in some domains, convergence cannot be expected among persons who are broadly equal in their capacity to reason, acquire information, assess evidence and arguments, and engage in critical reflection, while accepting what has been labeled as "the uniqueness thesis", that is the claim that in principle a body of evidence justifies at most one attitude toward a proposition (Feldman 2007: 205).

This seems to be the rationale behind the idea of reasonable pluralism as a view about justification that is relevant to political philosophy and deeply differs from relativism, namely the view that people that are equally endowed with the power of reason and apply common epistemic standards, while being willing to propose fair terms of cooperation, may be unable to agree upon the comprehensive philosophical, moral, and religious doctrines that underlay their (different) conceptions of justice (Cohen 1993: 282; Larmore 1996: 154). According to this view, disagreement is likely to occur and be resilient among broad epistemic peers. This qualification is important, as individuals may be defined as epistemic peers in either a strict or a broad sense. Under the strict reading, peerness requires both evidence possession and evidence processing to be the same. Under the broad reading, it only requires rational capacities and skills to be such that others cannot be taken to be more likely to be wrong than oneself (Elga 2007, Peters 2013, Matheson 2015). In the latter case, it may be true both that only a single conception is correct and that there are principled ways to adjudicate the issue, yet 
convergence is not likely to occur where differences in evidence, in the way it is assessed, and in background information affect the process of belief formation. This may sound too weak to claim pluralism, given that nothing here seems to prevent disagreements from being overcome by critical reflection and rational discussion, at least in principle. Both evidence and background information might be expected be shared by the end of the inquiry, provided that no principled limit is set to the possibility of argument and that people exercise their power of reason. However, a key assumption behind the notion of a reasonable pluralism is that even "reflective convergence" is not to be expected at least in domains where the process of belief formation is peculiarly complex, like the moral domain (Cohen 1993: 281-82). ${ }^{4}$ Reasonable pluralism seems thus to devise a kind of normative pluralism that is designed to steer clear of relativism. It preserves the claim that disagreements may not admit of rational resolution, while carefully avoiding to claim that there may be many different, fundamentally alternative ways of forming beliefs and judgment, yet no facts by virtue of which one may be better than others. Political liberalism is intended to answer this predicament by advancing justice as fairness as a freestanding conception of justice that abstains from ontological and epistemic commitment in the justification of political principles. In the next sections, I argue that this is an unstable position and suggest that an epistemic view of deliberation may be better suited to making sense of political justification. The latter view, however, is bound to dispense with normative pluralism.

\section{Pluralism and Reasonable Disagreement}

The issue with pluralism, understood as outlined above, is different from the questions arising in connection with value pluralism, understood as the doctrine that there is a plurality of incommensurable and mutually incompatible, equally ultimate values. In fact, as noted by Larmore (1996: 154), the latter is itself a controversial doctrine about the nature or the source of value, which is not more likely to attract convergence than any other. What is meant to raise the problem of pluralism in the present context is rather the view that a plurality of reasonable and yet incompatible religious, moral, and philosophical doctrines is "the normal result of the exercise of human reason" in a democratic society (Rawls 1993: xviii). Pluralism thus follows from the possibility of reasonable disagreement, where people are taken to be reasonable if they are willing to accept what Rawls terms the burdens of judgment - together with being willing 
to propose fair terms of cooperation and to abide by them, provided that others do so (Rawls 1993: 54). In explaining how reasonable disagreement is possible, Rawls of course rules out irrationality and lack of intelligence as well as the idea that different views reflect different interests, rejecting them as "too easy" answers to the question at stake. What needs to be explained is indeed that disagreement occurs among people who apparently hold their views in good faith and are broadly equal in their capacity for reasoning and critical reflection, given that they all "share a common human reason". The sources of disagreement must therefore be "the many hazards involved in the correct (and conscientious) exercise of our powers of reason and judgment in the ordinary course of political life" (Rawls 1993: 55-56). This means that reasonable people (1) do not affirm their views dogmatically, (2) do not endorse significantly different norms of belief formation - thus providing no case for epistemic pluralism (Weinberg, Stich, Nichols 2001) - and (3) do not use their powers of reason incorrectly. The sources of disagreement listed by Rawls are thus designed to account for disagreement among broad epistemic peers. People are not taken to possess exactly the same evidence and to process it in exactly the same way, yet they are taken to be in an equally good epistemic position regarding the issue at stake. The burdens of judgment are traced back to the following circumstances note that only the last two are specific to the moral and political domains.

1) evidence can be conflicting and complex, and thus hard to assess and evaluate;

2) even where we agree abut the considerations that are relevant, we may disagree about their weight.

3) to some extent, all concepts are vague and thus subject to interpretation;

4) the way we assess evidence, and weigh moral and political values, is shaped to some extent by our total experience, which naturally differs;

5) different normative considerations may carry different force, and it is difficult to make an overall assessment difficult;

6) setting priorities and making adjustment among different moral and political values involves hard decisions that may seem to have no clear answer (Rawls 1993: 57)

The implication of the burdens of judgment is that "reasonable people do not all affirm the same comprehensive doctrine", conceived as an intelligible view of the world that draws upon a tradition of thought and covers major religious, philosophical and moral aspects of 
human life (Rawls 1993: 59). Rawls' proposal, however, differs from those advanced in the peer disagreement literature. On the one hand, Rawls clearly holds that it is both rational and reasonable for each party to hold their own judgment true (Rawls 1993: 60). The rationale for this is that each is likely to have good reason to be confident, on reflection, in their own judgment. While understanding that alternatives are reasonable from different perspectives, it seems that in this case one may be justified in thinking that one's own assessment of the evidence and weighted considerations are on the right track, along with one's interpretations of vague concepts and the relative force of one's normative considerations and priority-setting. Given that controversial beliefs are arrived at in ways that one is confident with and that there are no specific grounds for doubting one's own exercise of the power of reason, disagreement appears to be no defeater. ${ }^{5}$ This rules out the argument that peer disagreement provides us with a reason for revising our judgment, suspending our belief, or lowering our confidence in the relevant propositions as a way to conciliate with others whose judgment is equally likely to be right, as proponents of so-called conciliatory views advise, and certain trends in deliberative democracy seem to suggest by claiming, for example, that economizing on moral disagreement or balancing one's own and others' perspectives is both the expected and desirable output of deliberation (Gutman, Thompson 2004: 134, Goodin 2003: 183).

On the other hand, although reasonable people are justified in holding to their views in the face of disagreement, they are not in a position to "insist, when fundamental political questions are at stake, on what they take as true" (Rawls 1993: 61). This marks a departure from the "steadfast views" advanced in the literature as an alternative to conciliatory views. The rationale seems to be twofold. First, reasonable people recognize that their own doctrine is "but one reasonable doctrine among others" and that therefore they can raise no special claim over other equally reasonable people who affirm different views (Rawls 1993: 60). Second, insisting on the truth of one's own view would amount to claiming legitimate authority to take it as a basis for deciding on the constitutional essentials or basic questions of justice, and to use coercive power to repress other comprehensive views that are not unreasonable - which itself counts as unreasonable as long as a shared basis of justification for comprehensive doctrines is lacking (Rawls 1993: 61). In this respect, being reasonable is not just an epistemological stance, but is connected with "the political ideal of a democratic citizenship that includes what free and equal citizen can require of each other with respect to their reasonable comprehensive views" 
(Rawls 1993: 62). By granting that each party is justified in believing their own comprehensive doctrine to be true, the burdens of judgment limit what may be reasonably justified to others.

Rawls' treatment of disagreement thus neither recommends conciliation, nor can be taken to vouch for a steadfast view. What is specific to Rawls' solution is rather to hold that political justifications should avoid ontological and epistemic commitment. In the face of reasonable disagreement, a political conception of justice should be free-standing with respect to the ontological and epistemic commitments of comprehensive doctrines in order to be possibly justified to those who are bound by it. This means that, while being a part "that fits into and can be supported by" any reasonable comprehensive doctrine, it is not derived from any of them and does not take stance on whether one of them is true (Rawls 1993: 12, 128). The limits set on what can be justified to others make no reference to truth here, given that reasonableness, not truth, is the standard, and reasonableness follows from a specifically political moral psychology that draws on "a scheme of concepts and principles for expressing a political conception of the person and an ideal of citizenship" (Rawls 1993: 87) What makes the latter specifically political is the fact that they are not advanced as truths about human nature to be settled by metaphysical reflection or empirical discovery, but rather as a set of concepts and principles of practical reason entailed by the fundamental ideas that are found in the political culture of democratic societies (Rawls 1993: 13-14, 86-87, 126-127). Note that, according to this reading, the part of moral psychology that is specific to political philosophy turns out to be sui generis, given that it can be neither covered by a priori philosophical reasoning, nor by a posteriori scientific psychology. This results in the idea that public justification only indirectly depends on reasonable comprehensive doctrines. Public justification is only possible insofar as an overlapping consensus among comprehensive doctrines is found on a political conception of justice that provides common ground for public discussion, yet it is worked out by citizens "within the bounds of the political", as the contents of comprehensive doctrines play "no normative role" in this context (Rawls 1996: 387-88). In other words, public justification conforms to the sui generis standards of political justification that are settled by political liberalism as a free-standing conception of justice:

Political liberalism does not use the concept of moral truth applied to its own political (always moral) judgments. Here it says that political judgments are reasonable or unreasonable; and it lays out political ideals, principles, and standards as criteria of the 
reasonable. These criteria in turn are connected with the two basic features of reasonable persons as citizens: first, their willingness to propose and to abide by, if accepted, what they think others as equal citizens with them might reasonably accept as fair terms of social co-operation; and, second, their willingness to recognize the burdens of judgment and accept the consequences thereof. For the political purpose of discussing questions of constitutional essentials and basic justice, political liberalism views this idea of the reasonable as sufficient. The use of the concept of truth is not rejected or questioned, but left to comprehensive doctrines to use or deny, or use some other idea instead. (Rawls 1996: 395-396)

\section{Political Justification and Truth}

Reasons for resisting this conclusion have been put forward in the literature. In this section, I will consider Cohen's objection and draw some conclusions that bear on Habermas' epistemic view of deliberation. Cohen argues that in political justification we cannot "do without the concept of truth" as Rawls contends, because truth is connected "with the concept of belief and meaning, both fundamental in the account of thought" and (hence) with the very idea of a reasoning process (Cohen 2009: 13-14)). First, belief is commonly taken to "aim at truth", in that truth is the standard of correctness for beliefs and their behavior is thus governed by rational norms or subject to ceteris paribus laws connected with their semantic properties: for instance, it is rational to revise a belief that $\mathrm{P}$ when confronted with evidence that $\mathrm{P}$ is false (Cohen 2009: 13). In the same vein, believing that $Q$ and (if $Q$ then $P$ ) leads to believing that $\mathrm{P}$, perceiving that $\mathrm{P}$ leads to believing that $\mathrm{P}$, believing that an action promotes a desired state of affairs leads to performing that action and so on. In this sense, beliefs are routinely taken to be functional states whose representational properties are connected with the role they play in psychological processes (Fodor 1985, see also Millikan 1984: 139-40). Second, reasoning processes are commonly conceived as rational transitions among mental states insofar as they are governed by epistemic norms connected with truth - for example, norms that require them to be truth-preserving or reliably truth-conducive (Cohen 2009: 14, see Goldman 2012; Goldman 2014). Given that truth is the standard of correctness for belief and reasoning 
processes are governed by epistemic norms, deliberation may be said to aim for truth in the sense that, when deliberating whether to believe that P we "aim to determine whether $\mathrm{P}$ is true" (Cohen 2009: 13-14). Cohen is drawn to conclude that we can hardly imagine what it would mean to conduct political justification without recourse to the concept of truth (Cohen 2009: 15). The point is that, on this view, it is inconsistent to allow judgment and reasoning in political justification while contending that the concept of truth has no application in this context:

[...] Rawls' proposal is to endorse a cognitivist understanding of political conceptions of justice and political argument on which notions of judgment, reasoning, and argument are fully in play, while denying the availability of the concept of truth within such conceptions. The concern is specifically with the concept of truth, and the reason for leaving it out cannot be that political discourse traffics in something other than truth bearers. Someone might offer that rationale for the view that truth has no place in political argument, but not if they think of political argument as an exercise of public reason. (Cohen 2009: 19) ${ }^{6}$

Cohen's suggests, however, that political liberalism can be emended by establishing a political concept of truth that is tailored to suit the need for a cognitive understanding of political justification without dispensing with reasonable pluralism. The point is that it is not truth itself that is divisive and prevents agreement. The latter view is motivated by the fact that two inconsistent propositions cannot both be true, while they may both be reasonable to believe. Thus, asserting that a particular account of justice is true commits one to denying that any conflicting accounts are true, while asserting that it is reasonable is compatible with accepting that others are reasonable too. Reasonableness is compatible with pluralism, while truth is not, because of its "singularity": the singularity of truth seems to make it incompatible with pluralism and therefore unsuitable for public reason (Cohen 2009: 29). Cohen's argument against this view comes in three steps. First, public reason clearly admits of no less divisive concepts and standards. Given that there is more than one political conception of justice, we may disagree about which view is most reasonable. Furthermore, we may disagree about what justice requires, for instance about whether it requires equal or maximin basic liberties. In such cases, we cannot all be right, although we are reasonable. Second, deploying the concept of 
truth in raising our respective claims within public reason would add nothing to the disagreement we face: it would just express it. Third, the concept of truth may be used within public reason, provided that we endorse a reasonable attitude toward truth itself - that is, provided that we acknowledge that being true is not a sufficient condition for a proposition to play a role in political arguments, since reasonable people acknowledge that true propositions may fail to gain acceptance from others that are equally reasonable and are thus prepared to find reasons that are compelling to others (Cohen 1996: 100, As a consequence, not all true propositions count as relevant within public reason because the truth of a proposition does not "suffice [...] to make an appeal to it appropriate in political justification" (Cohen 1999: 31-32).

On this view, truth claims need not be denied application in the political domain, but their relevance is constrained by reasonableness. The truth of a proposition is relevant to political justification only insofar as it rests on shared ground and therefore "an appropriate but limited role of judgments about truth" is licensed "on that shared ground" Cohen 2009: 35). Once so qualified, the concept of truth may be kept and may play a role in political justification. This debunks the argument against public reason that was initially suggested, namely that public reason cannot support a cognitivist view of political justification because doing without truth precludes grasping what an argument, a judgment, or a reasoning process can possibly amount to. Cohen suggests that the concept of truth in play here should be labeled "the political concept of truth" (Cohen 2009: 37). ${ }^{7}$

Does this proposal square with the role of truth in cognitive processes? The political conception is designed to be "suited for the purposes of political reflection and argument in a pluralistic democracy, characterized by doctrinal disagreements" (Cohen 2009: 3). Suppose people disagree on the principles of justice or on what justice requires. We have seen that this is entirely possible, given that there is a multitude of reasonable conception of justice. Their disagreement may be expressed in this context by saying that they disagree about the truth of a proposition P. Now suppose that deliberation leads them to overcome their disagreement by reasoning from shared premises. On the assumption that they exercise their rational powers correctly, the reasoning process will lead them to the truth, if the premises they share are themselves true, but will otherwise lead them to the wrong deliberative output. Reasoning correctly from false premises, they will be drawn to a false conclusion, which cannot possibly count as a desirable outcome if we take deliberations to aim at truth. If the cognitive role of truth is to be preserved, we should rather want false premises to be revised - ideally at least - 
in order to avoid false conclusions. Thus, it is hard to see how the argument for the relevance of truth to the cognitive understanding of political argument can be squared with the view that false propositions may license correct conclusions within public reason. Public reason requires that arguments be carried out on shared ground, yet it would be wrong to accept a proposition that follows from false premises because they are reasonable. We cannot require truth to play a role in public reason and be unconcerned about accepting consequences that follows from false premises.

Yet Cohen must allow that a false conclusion is acceptable, provided that it follows from considerations that are reasonable, although false.. Public reason here draws on reasons that are shared across reasonable conceptions and provide no independent ground on which to sort out false premises. Permissible considerations thus are likely to include false premises, as long as there is a variety of reasonable conceptions of justice that cannot be jointly true, and some of them will entail false principles or beliefs. Cohen thus claims, not only that being true is not a sufficient condition to count as a reason in political justification, but also that it is not a necessary condition either, given that some views of justice, while false, may be reasonable: "what matters for democracy's public reason is reasonableness, not truth" (Cohen 2009: 31).

It has been argued on this basis that Cohen's political concept of truth is expressive rather than operative, because it does no real work in political justifications. More specifically, it does not perform the function of separating considerations that could count in deliberation from considerations that could not, given that false propositions play exactly the same justificatory role as true ones under the constraints imposed by reasonableness to the use of truth in political argument (Butler 2016). Participants can thus express their disagreement in terms of conflicting truth claims, but cannot appeal to truth according to the role it plays in deliberation - where false beliefs are subject to revision because "when we deliberate about whether to believe that $\mathrm{P}$, we try to determine whether P (is true)" (Cohen 2009: 13-14). In this sense, Cohen's alternative seems forced to retreat to epistemic abstinence, because it precludes deliberation from playing any epistemic role. The crux is that Cohen cannot allow what counts as shared ground to be shaken by considerations about truth, as truth would constrain the reasonable in this case, rather than the contrary. Yet this is not compatible with maintaining that truth plays a role in political justification. If truth is to be relevant in political justification, we should expect false premises to be revised wherever possible in order to avoid false conclusions. Thus, any proposition within the set of propositions that count as shared ground 
should be possibly assessed for truth and removed should it turn out false. Any, consideration relevant to the truth of such propositions, including considerations that concern the comprehensive doctrines on which they draw, would therefore be relevant to political justification. In fact, it would contribute to shape the space of public reason. The very idea of imposing a reasonableness constraint on public reason would collapse.

A converse case is made by Ingham (2016) for showing that comprehensive doctrines may be affected by arguments that move from shared true premises. As illustrated by Cohen (2009: 30-31), disagreements within public reason may concern some proposition that can be inferred from a reasonable comprehensive doctrine when combined with auxiliary premises that are common ground. By hypothesis, in such cases, people may reasonably argue within public reason to the effect that the target proposition is false and, by modus tollens, any reason to reject it will count in this context as a public reason to reject some of the premises from which it is derived. Shared auxiliary premises, however, are allegedly true. Therefore, some of the premises that draw on the relevant comprehensive doctrine must be false, It follows that one can argue from within public reason to the effect that a comprehensive doctrine is, at least partly, false.

While the former case showed that considerations concerning the truth of comprehensive doctrines may affect public reason, the latter shows that arguments conducted within public reason may affect the truth of comprehensive doctrines. The upshot is that granting the concept of truth an "operative" role in political justification leaves no room for constraining public reason. As long as we take the concept of truth to be connected to the cognitive properties of political justification, we are bound to conclude that we cannot have both a reasonability constraint on public reason and a cognitivist understanding of political justification.

\section{Pluralism and deliberation}

This comes as no surprise under a cognitivist understanding of belief and rationality. Evidence that $\mathrm{P}$ is false normally leads to revision of the belief that $\mathrm{P}$ and other the beliefs it entails. How can this fail to be relevant to public reason? It is sensible to claim that public reason is not committed to the whole truth (Cohen 2009: 34-5). Yet, we have seen that 
recognizing or failing to recognize the truth of a proposition may be relevant to deliberation, whether or not the proposition is presently included in the set of premises that count as shared ground. Conversely, arguments conducted within public reason to the effect that a proposition is false may affect the comprehensive doctrine from which the target proposition is derived. In other words, arguments to the effect that a certain proposition is true or false are likely to affect public reason with respect to the target proposition and the propositions it entails, regardless of whether they are shared ground. On the one hand, there is no way to insulate public reason from controversial truth claims connected to comprehensive doctrines, because the revision of beliefs that are no part of what counts as shared ground may affect the deliberative resolution of disagreements within public reason. On the other hand, there is no way to insulate comprehensive doctrines from arguments raised within public reason, as the latter may affect the former by way of mudus tollens.

What is taken to be common ground is therefore likely to shift over time as a result of arguments that turn on propositions which are far removed from what counts as shared among reasonable people at a certain time and place. It follows that what is relevant to public reason can be hardly be constrained by reasonability, given that no restriction can be set on the considerations that count in favor of or against political principles or public choices. Thus understood, however, public reason looks closer to Habermas' epistemic view of the public use of reason than to Rawls' distinctively political view. As long as the epistemic role of deliberation is left intact, the idea of a political liberalism is not just supplemented with a suitably constrained concept of political truth, but replaced by a rather demanding view of deliberation, according to which convergence among broad epistemic peers $i$ s to be expected at least in idealized conditions (Habermas 1995. 117-18)

Deliberation is in fact allowed to be guided by epistemic norms insofar as rightness is (taken to be) "on the same plane as propositional truth" and reasons enjoy causal powers with respect to beliefs (Habermas 1995: 123; Habermas 2003: 247-48; Forst, 2015). Although in this context rightness is something we discover by argument and the value of democracy goes therefore beyond the intrinsic and expressive properties of the democratic procedure, no metaethical commitment follows in relation to the standard against which deliberation is assessed (Landemore 2017). Rather, a two steps procedure is proposed for sorting out the right from the good that is supposedly free of substantive normative presuppositions (Habermas 1995: 11516). First, principles derived from conflicting comprehensive views of the good candidate to 
moral norms if and only if they are objective - in somewhat different terms, if they respond to agent-neutral reasons. Second, putative moral norms are tested by argument for their responsiveness to generalizable interests (Habermas 1990: 65-66, Habermas 1998: 81-82). Deliberation here preserves its natural epistemic properties, while the borderline between the good and the right is drawn according to what may turn out to be accepted in the light of argument. Thus, neither convergence on comprehensive truths, nor doctrinal agreement is required. In fact, convergence may be reached on moral norms that are not included in any comprehensive doctrine, because it is generated by the deliberative process and no restriction is set on what can be subject to revision. Cohen's proposal, on the contrary, is designed to prevent the output of deliberation to depart from comprehensive doctrines - given that deliberation cannot turn out to backfire on what is taken to be shared ground. In this sense, politically true beliefs are granted to preserve given doctrines. One may wonder how this might add anything epistemic to the idea of an overlapping consensus. Conversely, where deliberation is credited with epistemic properties, it can be taken to yield genuine public reasons precisely because deliberative outputs differs from overlapping consensus in that they do not depend on contingent agreement among comprehensive doctrines (Habermas 1996: 114, Forst 2012: 9293).

On the latter view, pluralism is addressed in a different way. Deliberation in fact does not need to "bracket the pluralism of convictions and world-views from the outset", because it is not designed to record overlapping consensus, but to yield a "we-perspective" that can be naturally expected to emerge as the practice of argumentation "enjoins those involved to an idealizing enlargement of their interpretive perspectives." (Habermas 1995: 117). An attractive feature of this framework is that reasonable and unreasonable people are treated in the same way, as the requirements for participating in public deliberation are fairly minimal. ${ }^{8}$ Normative pluralism however fades away. While a fallibilistic attitude that comes close to accepting the burdens of judgment is retained, in fact, disagreement can only be contingently rational here, since no principled restriction is set on arguing about both evidence and the way it is assessed, so that even the most well-entrenched beliefs and basic epistemic principles are subject to revision (Habermas 1995: 117-18). On this reading, the burdens of judgment set no principled constraint to public arguments designed to screen out ethical values from moral norms. Having formed their moral beliefs in different ways and in accordance with different religious or metaphysical worldviews, people may happen to diverge in what they advance as putative 
moral norms, yet nothing prevents disagreement to be met by argument. Conversely, the idea that there is a plurality of conceptions of the good life is preserved only insofar as these are credited with raising a sui generis claim to authenticity (Habermas 1995: 125-26). Pluralism here is descriptive, not normative.

It has been suggested in this connection that the rationale for endorsing reasonable pluralism is that there is something specific to political morality connected with the social function that agreement performs in the political domain. On this reading, politics diverges from both epistemology and ethics because of the pressure to agree on a cooperative scheme (MacMahon 2006: 8 ff., 33, 69-70). Descriptive pluralism here may seem enough to raise a normative problem about the conditions under which agreement is reached, as convergence under epistemically ideal conditions is no solution for actual disagreements and actual people cannot wait for rightness to emerge at the end of the inquiry before engaging in social cooperation. There are two problems with this view, however. First, idealizations are involved in any view of public reason and Rawls' abstinent view fares no better in this respect than fullblown epistemic conceptions of deliberation (Enoch 2015: 117-18, 127 ff.). Second, epistemically ideal conditions are better understood as a standard against which arguments are assessed rather than as a set of conditions to be met in order for something to count at all as a justification (Putnam 1981: 55). Although defeasible, arguments that fall short of meeting epistemically ideal conditions may still supply best evidence available for the time being and thus, while imperfect and subject to revision, attract sufficient (provisional) convergence, provided that public discussion abides by ordinary epistemic norms. In this respect, political disagreement is not special. Also, supplementing deliberation with a voting procedure seems sensible wherever arguments de facto fail to settle disagreement (Peters 2013). Mixed models have been proposed in this spirit over the last decades to combine deliberative and aggregative theories of democracy, building on the idea that, while it may not be realistic to expect public deliberation to generate consensus on any specific issue, it is not unrealistic to expect that a meta-consensus can be generated on the relevant dimensions of choice (Dryzek, List 2003). Nothing here suggests that disagreement cannot be met by argument or that it can only be met by refraining from epistemic commitment.

Reasonable pluralism seems to raise a claim that is more demanding than descriptive pluralism, while avoiding collapse into relativism, and to recommend epistemic abstinence as to demarcate the space of public reason. This is an unstable position. On the one hand, it is 
questionable that a genuine case for normative pluralism can be made on its basis. The burdens of judgment may account for how disagreement arises among broad epistemic peers, but provide no principled reason to think that it cannot be addressed by critical reflection and public argument. On the other hand, it is questionable that public reason can be constrained by reasonableness. For endorsing epistemic abstinence prevents political justification from drawing on a cognitivist conception of belief and reasoning, while taking the latter seriously ultimately dismantles the case for normative pluralism. The upshot is, I think, unsurprising. Normative pluralism - be it reasonable or not - conflicts with the idea that there is something about political justification that stands beyond relativization.

\section{References}

Bagnoli, C. (2015). Constructivism in Metaethics. Stanford Encyclopedia of Philosophy http://plato.stanford.edu/archives/spr2015/entries/constructivism-metaethics/

Boghossian, P. (2006), Fear of Knowledge: Against Relativism and Constructivism, OUP, Oxford.

Butler, J. (2016), "Finding Space for the Truth: Joshua Cohen on Truth and Public Reason" Res Publica (forthcoming) DOI 10.1007/s11158-016-9333-2.

Cohen, J. (1993), "Moral Pluralism and Political Consensus” in D.Copp, J. Hampton, J. Roemer (eds.), The Idea of Democracy, CUP, Cambridge: 270-291.

- (1996), "Procedure and Substance of Deliberative Democracy", in S. Benhabib (ed.), Democracy and Difference, Princeton: Princeton University Press: 95-119.

- (2009), “Truth and Public Reason”, Philosophy and Public Affairs (37)1: 2-42.

Davidson, D (2005), Truth and Predication, Cambridge (MA), Harvard University Press.

Dryzek, J., List C. (2003), "Social Choice Theory and Deliberative Democracy: A 
Reconciliation”, British Journal of Political Science 33: 1-28.

Elga, A. (2007), "Reflection and Disagreement", Noûs , 41(3): 478-502.

Enoch, D. (2010). "Not just a truthometer: Taking oneself seriously (but not too seriously) in cases of peer disagreement", Mind, 119, 953-997.

- $\quad$ (2015), “Against Public Reason”, in Sobel, P., Valletyne, P., Wall, S. (eds.), Oxford Studies in Political Philosophy. Volume 1, OUP, Oxford

Epstein, B. (2015), The Ant Trap: Rebuilding the Foundations of Social Science, OUP, Oxford.

Ferrara, A. (2014), The Democratic Horizon, CUP, Cambridge.

Feldman, R. (2005), “Reasonable Religious Disagreement”, in L.M. Antony (ed.), Philosophers without God, OUP: Oxford, pp. 194-205.

Fodor, J. (1985), “Fodor’s Guide to Mental Representations”, Mind 94(373): 76-100.

- $\quad$ (1998), Concepts: Where Cognitive Science Went Wrong, OUP, Oxford.

Fogelin, R. (1985), “The Logic of Deep Disagreements”, Informal Logic, 7: 1.8

Forst, R. (2012), The Right to Justification, Columbia University Press.

(2015), "Noumenal Power", The Journal of Political Philosophy 23(2). 111-127.

Goldman, A. (2010), "Epistemic Relativism and Reasonable Disagreement”, in R. Feldman and T. Warfield (eds.), Disagreement, OUP, Oxford: 187-215.

- $\quad$ (2012). Reliabilism and Contemporary Epistemology, OUP, Oxford.

- (2014), "Social Process Reliabilism: Solving Justification Problems in Collective Epistemology”, in J. Lackey (ed.), Essays in Collective Epistemology, Oxford: Oxford University Press, pp. 11-41. i[s] 
Goodin, R. (2003), Reflective Democracy, OUP, Oxford.

Guala, F. (2016), Understanding Institutions: The Science and Philosophy of Living Together, Princeton University Press, Princeton.

Gutman, A. Thompson, D. (2004), Why Deliberative Democracy?, Princeton University Press, Princeton.

Ingham, S. (2016) “A Dilemma for Public Reason”, SSRN: http://dx.doi.org/10.2139/ssrn.2315235

Habermas, J. (1984), Vorstudien und Ergänzungen zur Theorie des kommunikativen Handelns, Suhrkamp, Frankfurt a. M.

- (1990), Moral Consciousness and Communicative Action, Polity Press, Oxford

- (1995), "Reconciliation Through the Public Use of Reason”, The Journal of Philosophy (92)3: 109-131

- $\quad$ (1998), The Inclusion of the Other, MIT Press, Cambridge (MA)

- $\quad$ (2003), Truth and Justification, MIT Press, Cambridge (MA)

Hare, R.M, (1991), The Language of Morals, Oxford: OUP.

Landemore, H. (2017), "Beyond the Fact of Disagreement? The Epistemic Turn in Deliberative Democracy", Social Epistemology 31(3): 277-295

Larmore, Ch. (1996), The Morals of Modernity, Cambridge. CUP

MacMahon, C. (2009), Reasonable Disagreement: A Theory of Political Morality, CUP, Cambridge

Matheson, J. (2015), "Disagreement and Epistemic Peers." Oxford Handbooks Online in Philosophy. (2015). DOI: 10.1093/oxfordhb/9780199935314.013.13. 
Millikan, R. (1984), Language, Thought, and Other Biological Categories, MIT Press, Cambridge (MA).

Peter, F. (2013), The Epistemic Circumstances of Democracy, in M. Brady, M. Fricker (eds.), The Epistemic Life of Groups: Essays on the Epistemology of Collectives, OUP, Oxford: 133-149.

Plunkett, D., Sundell, T. (2013), "Disagreement and the Semantics of Normative and Evaluative Terms", in Philosopher's Imprint (13)23: 1-37.

Putnam, H. (1975), Mind, Language, and Reality, CUP, Cambridge.

- $\quad$ (1981), Reason, Truth, and History, CUP, Cambridge

Rawls, J. (1971), A Theory of Justice, Harvard University Press, Cambridge (MA). 1993), Political Liberalism, New York: Columbia University Press. (1996) "Reply to Habermas", in Political Liberalism, revised edition, New York: Columbia University Press.

Rowlands, R. (2017), “The Epistemology of Moral Disagreement”, The Philosophy Compass (forthcoming) DOI:10.1111/phc3.12398.

Wedgwood, R. (2007). The Nature of Normativity. New York: Oxford University Press.

Weineberg, Stich, S., Nichols, S. (2001), "Normativity and Epistemic Intuitions", in Philosophical Topics 29 (1-2): 429-470,

\footnotetext{
${ }^{1}$ Cf. Boghossian 2007: 39 ff., Hare 1991 148, see however Plunkett, Sundell (2013) for critical discussion.

${ }^{2}$ Externalism about social kinds is endorsed by Guala 2016, and at least suggested by Epstein 2015.

${ }^{3}$ This does not per se invite moral realism, because the distinction does not depend on whether moral facts are mind-dependent. Mind-dependence may be hold true, in keeping with moral constructivism of any variety, yet pluralism won't follow unless moral truths are relativized to particular points of view (Bagnoli 2015). What is
} 
specific to metaphysical pluralism is indeed the claim that facts vary according to contingent conceptions of what there is, and thus are relative to cultures, interests, and beliefs that may diverge across times and places. It is in this sense that, as noted above, metaphysical pluralism leaves no room for disagreement, because people holding different conceptions would be talking and thinking about different things (Boghossian 2007: 39 ff.).

${ }^{4}$ As we will see, this is different from Elga's suggestion that moral disagreement is intractable because there are no epistemic peers in the moral domain, since moral beliefs are embedded in a wider web of beliefs concerning moral and non moral issues (Elga 2007). In fact there is no reason to think that even deeply entrenched beliefs are immune to argument and thus it is sensible to consider not only that disagreements often take place against a background of broad moral and non moral agreement (Rowland 2016), but also that the latter can be established by argument when needed, unless this possibility is ruled out by further considerations about the nature of moral disagreement. Elga's point does not suffice to preclude epistemic peerness in the moral domain.

${ }^{5}$ See Wedgewood 2007: 261-63; Enoch 2010, Knanving 2014: 116-17.

${ }^{6}$ Of course, this would not be the case under a noncognitivist understanding of political discourse, yet the latter is not consistent with the idea of public reason (Cohen 2009: 17)

${ }^{7}$ Political truth is constrained by reasonableness both with respect to the truths implicated in comprehensive doctrines and with respect to philosophical theories of truth. However, it preserves the idea of correspondence under a metaphysically uncommitted reading by detaching the concept of truth from the philosophical theory of truth that takes correspondence to be a relation between propositions and a mind-independent metaphysical kind of entity - facts, for instance - working as truth makers (Cohen 2009: 3-4, 27). The political concept of truth thus advances nothing but the plain, ordinary view that flows from Aristotle's formulation that telling the truth amounts to "saying of what is, that it is, and of what is not, that it is not" (Metaphysics VII, 1011b 25-26). In fact, no ontological commitment is built into it (Davidson 2005: 126-27). Introducing a political concept of truth therefore does not amount to advancing a new, or different, or in any way restricted concept of truth. The restriction rather concerns the topics that are amenable to be assessed for truth in this context.

${ }^{8}$ The requirement to access public deliberation ultimately amounts to nothing more than a disposition to subject to the authority of argument, which is connected to the "socio-ontological constitution of the public practice of argumentation" in that participants mutually recognize themselves as minimally free and equal rational beings (Habermas 1995: 127, see Habermas 1990: 89 ff.), yet does not involve endorsing a specific political concept of persons and focus on the content of moral beliefs rather than on their being believed. For further discussion, see Ferrara 2014: 90-92 and Enoch 2015: 120 ff., 130 ff.) Any full-blown deliberative approach will of course characterize deliberative rationality in one way or another, yet it is questionable that this amounts to advancing a comprehensive doctrine (Rawls 1993: 132; cf. Forst 2012: 91-92). For one thing, the view that humans share a common power of reason is equally crucial, as we have seen above, to Rawls' ideas of reasonable disagreement and public reason. For another, a theory of deliberative rationality may rest on relatively minimal grounds by drawing on empirical theories designed to account for basic universal capacities of reasoning, agency, and social cognition (Habermas 1990: 31-32, 1984: 363 ff.). 